\title{
Coagulation under Mild Hypothermia Assessed by Thromboelastometry
}

\author{
Tobias Nitschke $^{\mathrm{a}}$ Philipp Groene $^{\mathrm{a}} \quad$ Alice-Christin Acevedo $^{\mathrm{a}}$ \\ Tobias Kammerer ${ }^{\mathrm{a}, \mathrm{b}}$ Simon T. Schäfer ${ }^{\mathrm{a}}$ \\ ${ }^{a}$ Department of Anesthesiology, University Hospital, LMU Munich, Munich, Germany; ${ }^{\text {b Department of }}$ \\ Anesthesiology and Intensive Care Medicine, University Hospital of Cologne, Cologne, Germany
}

\author{
Keywords \\ Coagulation · Hypothermia · Thromboelastometry · \\ Thromboelastography $\cdot$ Rotational thromboelastometry
}

\begin{abstract}
Introduction: While previous studies have shown a significant impact of extreme hypo- and hyperthermia on coagulation, effects of much more frequently occurring perioperative mild hypothermia are largely unknown. This study therefore aimed to analyze the effects of mild hypothermia using rotational thromboelastometry in vitro. Materials and Methods: Twelve healthy volunteers were included in this study. Standard thromboelastometric tests (EXTEM, INTEM, FIBTEM) were used to evaluate coagulation in vitro at 39, 37, $35.5,35$, and $33^{\circ} \mathrm{C}$. Beyond standard thromboelastometric tests, we also evaluated the effects of mild hypothermia on the TPA-test (ClotPro, Enicor $\mathrm{GmbH}$, Munich, Germany), a new test which aims to detect fibrinolytic capacity by adding tissue plasminogen activator to the sample. Data are presented as the median with 25/75th percentiles. Results: Extrinsically activated coagulation (measured by EXTEM) showed a significant increase in clot formation time (CFT; $37^{\circ} \mathrm{C}: 90 \mathrm{~s}[81 / 105]$ vs. $35^{\circ} \mathrm{C}: 109 \mathrm{~s}$ [99/126]; $p=0.0002$ ), while maximum clot firmness (MCF) was not significantly reduced. Intrinsically activated coagulation (measured by INTEM) also showed a significant increase in CFT $\left(37^{\circ} \mathrm{C}: 80 \mathrm{~s}\right.$ [72/88] vs. $35^{\circ} \mathrm{C}$ : $94 \mathrm{~s}$ [86/109]; $p=0.0002$ ) without significant effects on MCF. Mild hypothermia significantly increased both the lysis onset time $\left(136 \mathrm{~s}\left[132 / 151 ; 37^{\circ} \mathrm{C}\right]\right.$ vs. $162 \mathrm{~s}\left[141 / 228 ; 35^{\circ} \mathrm{C}\right]$, $p=0.0223)$ and lysis time $\left(208 \mathrm{~s}\left[184 / 297 ; 37^{\circ} \mathrm{C}\right]\right.$ vs. $249 \mathrm{~s}$ $\left.\left[215 / 358 ; 35^{\circ} \mathrm{C}\right] ; p=0.0259\right)$. Conclusion: This demonstrates
\end{abstract}

that even under mild hypothermia coagulation is significantly altered in vitro. Perioperative temperature monitoring and management are greatly important and can help to prevent mild hypothermia and its adverse effects. Further investigation and in vivo testing of coagulation under mild hypothermia is needed.

(c) 2021 S. Karger AG, Basel

\section{Introduction}

While normal core body temperature ranges from 36.5 to $37.5^{\circ} \mathrm{C}$, perioperative hypothermia is commonly defined when a patient has a temperature of $<36^{\circ} \mathrm{C}[1,2]$. Adverse effects, such as increased mortality, cardiac complications, or postoperative wound infection, correlate with perioperative hypothermia [2-4]. While previous studies have shown a significant impact of extreme hypoand hyperthermia on coagulation, effects of perioperative mild hypothermia on coagulation are mainly unknown $[5,6]$. Yet, especially mild hypothermia occurs frequently and is often disregarded as inevitable and insignificant in clinical practice [7].

Therefore, we conducted an in vitro study with blood samples of healthy volunteers evaluating the coagulation status at different temperature levels. We hypothesized that even a mild hypothermia of $35^{\circ} \mathrm{C}$ alters coagulation evaluated by thromboelastometry.

T.N. and P.G. contributed equally to this work. 
Table 1. Characteristics of healthy volunteers

\begin{tabular}{llllllllllrr}
\hline $\begin{array}{l}\text { Patient } \\
\text { No. }\end{array}$ & $\begin{array}{l}\text { Age, } \\
\text { years }\end{array}$ & Sex & $\begin{array}{l}\text { Height, } \\
\mathrm{cm}\end{array}$ & $\begin{array}{l}\text { Weight, } \\
\mathrm{kg}\end{array}$ & BMI & $\begin{array}{l}\text { Platelets, } \\
\text { G/L }\end{array}$ & INR & aPTT, s & $\begin{array}{l}\text { Fibrinogen, } \\
\mathrm{mg} / \mathrm{dL}\end{array}$ & $\begin{array}{l}\text { Creatinine, } \\
\mathrm{mg} / \mathrm{dL}\end{array}$ & $\begin{array}{l}\text { GFR, } \\
\mathrm{mL} / \mathrm{min} / 1.73 \mathrm{~m}{ }^{2}\end{array}$ \\
\hline 1001 & 34 & M & 190 & 95 & 26.3 & 170 & 0.9 & 26 & 233 & 1 & 95 \\
1002 & 31 & M & 175 & 72 & 23.5 & 267 & 1 & 27 & 238 & 0.8 & 118 \\
1003 & 27 & M & 185 & 81 & 23.7 & 205 & 1.1 & 27 & 221 & 0.9 & 118 \\
1004 & 27 & M & 188 & 83 & 23.5 & 239 & 1 & 26 & 257 & 1 & 105 \\
1005 & 30 & M & 180 & 85 & 26.2 & 277 & 1 & 27 & 186 & 1.3 & 76 \\
1006 & 28 & M & 176 & 73 & 23.6 & 245 & 1 & 24 & 258 & 0.8 & 123 \\
1007 & 29 & M & 185 & 81 & 23.7 & 262 & 0.9 & 26 & 202 & 0.9 & 113 \\
1008 & 28 & M & 170 & 70 & 24.2 & 282 & 1 & 27 & 250 & 1.1 & 94 \\
1009 & 25 & M & 181 & 80 & 24.4 & 323 & 1 & 27 & 242 & 1 & 106 \\
1010 & 31 & M & 189 & 75 & 21.0 & 213 & 1 & 26 & 198 & 0.9 & 116 \\
1011 & 28 & M & 176 & 67 & 21.6 & 310 & 1 & 26 & 225 & 0.9 & 113 \\
1012 & 28 & M & 182 & 68 & 20.5 & 290 & 1 & 25 & 197 & 0.9 & 117 \\
\hline
\end{tabular}

INR, internationalized normalized ratio; aPTT, activated prothrombin time; GFR, glomerular filtration rate.

\section{Materials and Methods}

The study was approved by the Ludwig Maximilian University ethics committee (No. 19-861) and performed in accordance with the Declaration of Helsinki. Written informed consent was obtained from healthy volunteers prior to study inclusion.

Blood samples of 12 healthy volunteers were analyzed within $2 \mathrm{~h}$ from blood sampling on commercially available rotational thromboelastometry (ROTEM) delta analyzers (TEM Innovations, Munich, Germany). Samples were evaluated at different temperatures $\left(33.0,35.0,35.5,36.0,37.0\right.$, and $\left.39.0^{\circ} \mathrm{C}\right)$. The temperature was set to a specific level in each ROTEM delta analyzer. Samples were stored for $30 \mathrm{~min}$ at the specific temperature (heating unit at ROTEM delta analyzer). The exclusion criteria were coagulation disorders (e.g., von Willebrand's disease) or intake of anticoagulants or platelet inhibitors within 30 days prior to study inclusion. Whole blood count as well as standard coagulation variables (internationalized normalized ratio [Thromborel S, Siemens Healthcare $\mathrm{GmbH}$, Erlangen, Germany] and activated prothrombin time [Actin FSL, Siemens Healthcare GmbH, Erlangen, Germany]) were evaluated for each volunteer.

Intrinsically activated thromboelastometry was determined using INTEM. Coagulation in this assay is initiated by ellagic acid and $\mathrm{CaCl}_{2}$, and thus via the intrinsic pathway. Extrinsically activated thromboelastometry was determined by EXTEM. The initiation of coagulation is done by tissue factor and $\mathrm{CaCl}_{2}$. FIBTEM analyses were performed to assess the fibrinogen function for clot formation. In this test the platelet function is inhibited by adding cytochalasin D.

Furthermore, TPA-test (ClotPro, Enicor GmbH, Munich, Germany) was used on the ROTEM delta analyzer to evaluate the fibrinolytic capacity. The test uses tissue plasminogen activator (TPA; $650 \mathrm{ng} / \mathrm{mL}$; concentration of the blood sample) to induce fibrinolysis. The assay is comparable to the EX-test except that TPA and coagulation is initiated by recalcification.

Tests were run for 3,600 s on 3 ROTEM delta analyzer machines in a randomized order. Quality controls were routinely performed as recommended by the manufacturer.

The parameters provided are the clotting time (CT; time from initiation of the clotting process to $2 \mathrm{~mm}$ clot amplitude), clot formation time (CFT; time from CT until a clot amplitude of $20 \mathrm{~mm}$ is reached), A5 (clot amplitude 5 min after CT), A10 (clot amplitude 10 min after $\mathrm{CT}$ ), and maximum clot firmness (MCF; maxi- mum amplitude of the clot). Additionally, lysis time (LT; time from CT until 50\% lysis of MCF) and lysis onset time (LOT; time from CT until 15\% lysis of MCF), as well as maximum lysis (ML; degree of lysis in relation to MCF during measurement), are provided by the TPA-test.

\section{Statistics}

Data are presented as the median with percentiles (25th/75th) unless otherwise indicated. Statistical analysis was performed using GraphPad Prism 8.4 (GraphPad, La Jolla, CA, USA). Statistical differences between conditions were analyzed using one-way ANOVA and Tukey's multiple comparison test. Alpha error was adjusted for multiple testing $(p=0.05 / n)$.

\section{Results}

The characteristics of healthy volunteers are displayed in Table 1. In a first step we analyzed the impact of a wide range of temperature differences in a subgroup of samples to confirm the functionality of our approach by comparing the results to prior studies.

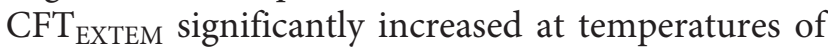
$33^{\circ} \mathrm{C}$ compared to $37^{\circ} \mathrm{C}\left(37^{\circ} \mathrm{C}\right.$ : $90 \mathrm{~s}[81 / 105]$ vs. $33^{\circ} \mathrm{C}$ : $126 \mathrm{~s}[117 / 142] ; p=0.0057$; Fig. 1a) and decreased at temperatures of $39^{\circ} \mathrm{C}\left(37^{\circ} \mathrm{C}: 90 \mathrm{~s}[81 / 105]\right.$ vs. $39^{\circ} \mathrm{C}: 79 \mathrm{~s}$ [66/88]; $p=0.0246)$. $\mathrm{CT}_{\mathrm{EXTEM}}$ only differed between samples at $33^{\circ} \mathrm{C}$ and $39^{\circ} \mathrm{C}(79 \mathrm{~s}[71 / 88]$ vs. $61 \mathrm{~s}[58 / 68] ; p=$ $0.0045) . \mathrm{MCF}_{\text {EXTEM }}$ was reduced at $33^{\circ} \mathrm{C}$ compared to $37^{\circ} \mathrm{C}\left(33^{\circ} \mathrm{C}: 56 \mathrm{~mm} \mathrm{[54/58]} \mathrm{vs.} 37^{\circ} \mathrm{C}: 59 \mathrm{~mm}\right.$ [56/60]; $p=0.0437)$ and did not differ between $37^{\circ} \mathrm{C}$ and $39^{\circ} \mathrm{C}$ $(p=n s)$.

$\mathrm{CFT}_{\text {INTEM }}$ increased at temperatures of $33^{\circ} \mathrm{C}(119 \mathrm{~s}$ [103/132]; $p=0.0013)$ compared to $37^{\circ} \mathrm{C}(80 \mathrm{~s}[72 / 88])$ and $39^{\circ} \mathrm{C}(62 \mathrm{~s}$ [57/69]; $p<0.0001$; Fig. $1 \mathrm{~b})$ and was also different between samples at $37^{\circ} \mathrm{C}$ and $39^{\circ} \mathrm{C}(p=0.003)$. $\mathrm{CT}_{\text {INTEM }}$ was prolonged at $33^{\circ} \mathrm{C}$ compared to $39^{\circ} \mathrm{C}$ (215 s [199/232] vs. 167 s [159/189]; $p=0.0044)$. There 

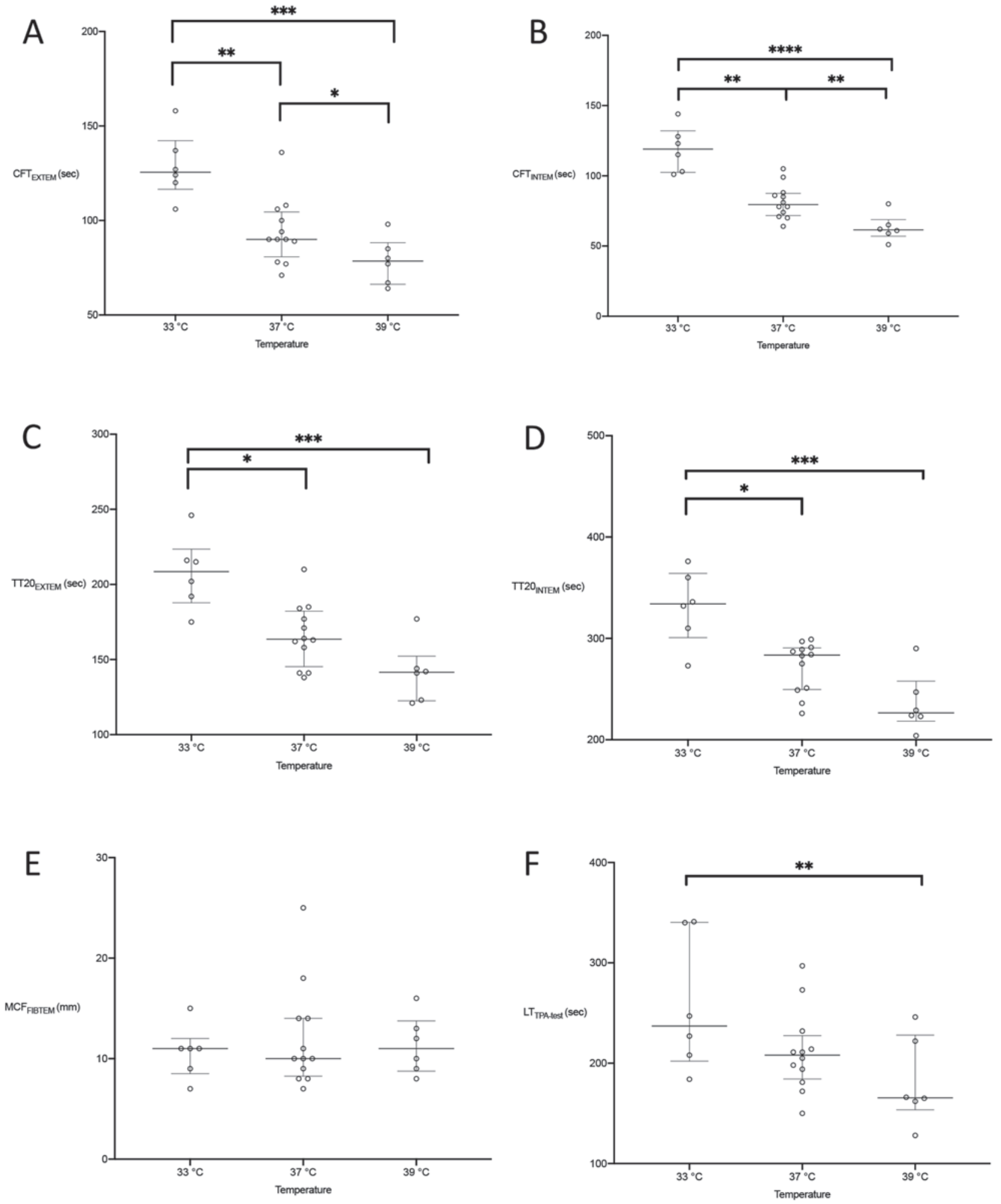

Fig. 1. Thromboelastometric tests performed at 33,37 , and $39^{\circ} \mathrm{C}$. Graphs show the median and interquartile range. A CFT (EXTEM). B CFT (INTEM). C TT20 (EXTEM). D TT20 (INTEM). E MCF (FIBTEM). F LT (TPAtest). 

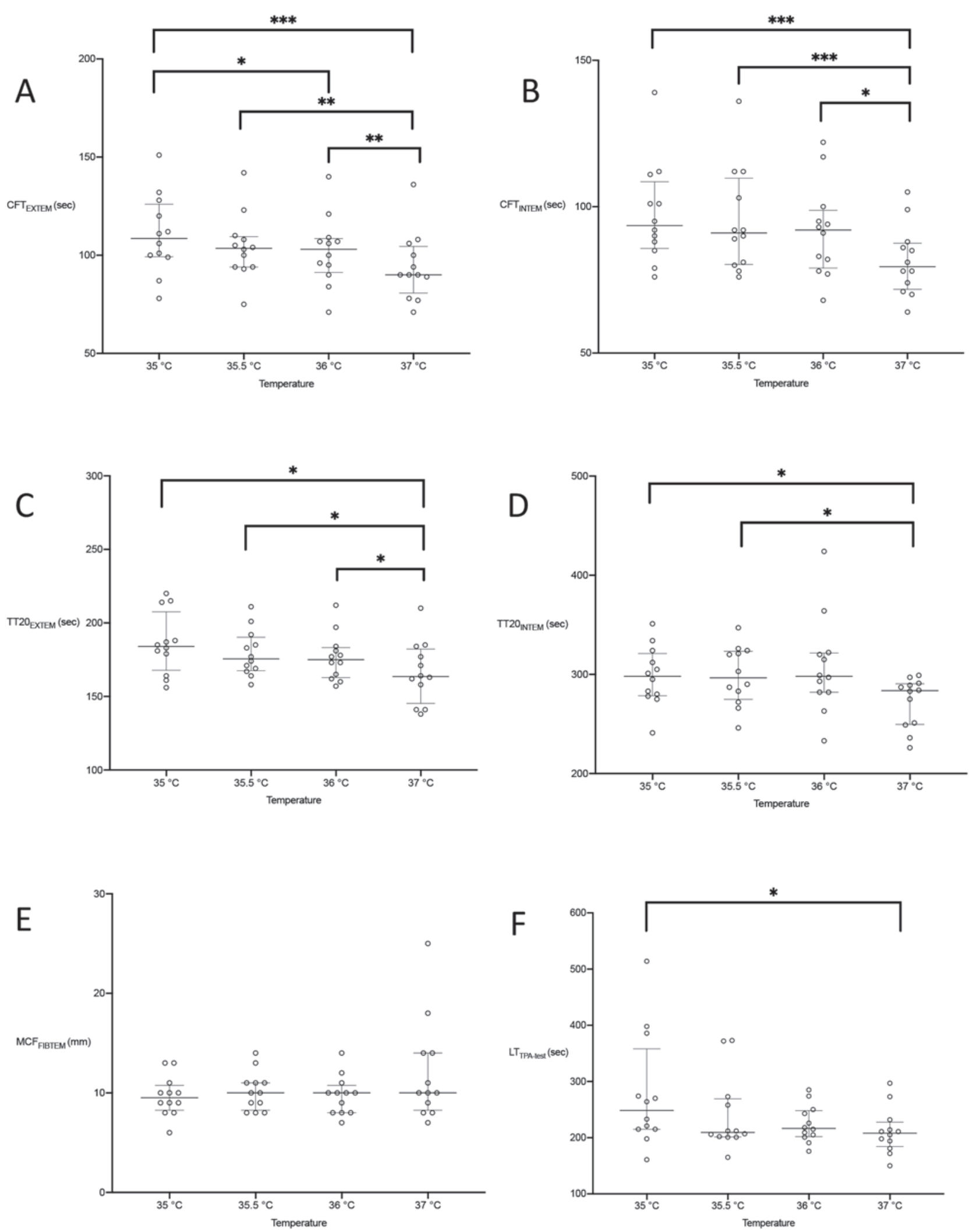

Fig. 2. Thromboelastometric tests performed under mild hypothermia $\left(35,35.5,36^{\circ} \mathrm{C}\right)$ and at $37^{\circ} \mathrm{C}$. Graphs show the median and interquartile range. A CFT (EXTEM). B CFT (INTEM). C TT20 (EXTEM). D TT20 (INTEM). E MCF (FIBTEM). F LT (TPA-test). 
Table 2. Data for thromboelastometric parameters

\begin{tabular}{|c|c|c|c|c|c|c|}
\hline & $33.0^{\circ} \mathrm{C}(n=6)$ & $35.0^{\circ} \mathrm{C}(n=12)$ & $35.5^{\circ} \mathrm{C}(n=12)$ & $36.0^{\circ} \mathrm{C}(n=12)$ & $37.0^{\circ} \mathrm{C}(n=12)$ & $39.0^{\circ} \mathrm{C}(n=6)$ \\
\hline $\mathrm{CT}_{\text {EXTEM }}, \mathrm{s}$ & $79(71 / 88)$ & $77(69 / 83)$ & $76(70 / 78)$ & $73(70 / 78)$ & $71(65 / 76)$ & $61(58 / 68)$ \\
\hline $\mathrm{CFT}_{\text {EXTEM }}, \mathrm{s}$ & $126(117 / 142)$ & $109(99 / 126)$ & $104(94 / 110)$ & $103(91 / 109)$ & $90(81 / 105)$ & $79(66 / 88)$ \\
\hline TT20 EXTEM, $s$ & $209(188 / 224)$ & $184(168 / 208)$ & $176(168 / 190)$ & $175(163 / 183)$ & $164(145 / 182)$ & $142(123 / 152)$ \\
\hline $\mathrm{MCF}_{\text {EXTEM }}, \mathrm{mm}$ & $56(54 / 58)$ & $57(55 / 60)$ & $58(55 / 60)$ & $59(56 / 60)$ & $59(56 / 60)$ & $60(55 / 60)$ \\
\hline $\mathrm{A} 5_{\mathrm{EXTEM}}, \mathrm{mm}$ & $35(34 / 37)$ & $38(35 / 41)$ & $39(37 / 41)$ & $40(37 / 42)$ & $42(39 / 43)$ & $45(41 / 47)$ \\
\hline $\mathrm{CT}_{\text {INTEM }}, \mathrm{s}$ & $215(199 / 232)$ & $204(190 / 211)$ & $202(190 / 216)$ & $210(191 / 223)$ & $197(173 / 204)$ & $167(159 / 189)$ \\
\hline CFT $_{\text {INTEM }}, s$ & $119(103 / 132)$ & $94(86 / 109)$ & $91(80 / 110)$ & $92(79 / 99)$ & $80(72 / 88)$ & $62(57 / 79)$ \\
\hline TT20 INTEM, $\mathrm{s}$ & $334(301 / 364)$ & $298(279 / 321)$ & $297(275 / 323)$ & $298(282 / 322)$ & $284(250 / 291)$ & $227(218 / 258)$ \\
\hline $\mathrm{CT}_{\text {FIBTEM }}, \mathrm{s}$ & $74(69 / 78)$ & $71(67 / 84)$ & $72(67 / 73)$ & $74(69 / 81)$ & $67(62 / 77)$ & $58(56 / 61)$ \\
\hline $\mathrm{MCF}_{\text {FIBTEM }}, \mathrm{mm}$ & $11(9 / 12)$ & $10(8 / 11)$ & $10(8 / 11)$ & $10(8 / 11)$ & $10(8 / 14)$ & $11(9 / 14)$ \\
\hline $\mathrm{A} 5_{\text {FIBTEM }}, \mathrm{mm}$ & $10(8 / 11)$ & $9(7 / 10)$ & $9(7 / 10)$ & $8(7 / 10)$ & $10(7 / 12)$ & $10(8 / 13)$ \\
\hline $\mathrm{CT}_{\text {TPA-test }}, \mathrm{s}$ & $78(72 / 83)$ & $72(58 / 76)$ & $70(62 / 75)$ & $69(61 / 72)$ & $68(61 / 72)$ & $64(58 / 76)$ \\
\hline $\mathrm{LT}_{\mathrm{TPA} \text {-test }}, \mathrm{s}$ & $237(202 / 340)$ & $249(215 / 358)$ & $210(201 / 269)$ & $217(202 / 248)$ & $208(184 / 228)$ & $166(154 / 228)$ \\
\hline LOT $_{\text {TPA-test }}, \mathrm{s}$ & $162(134 / 217)$ & $162(141 / 227)$ & $140(133 / 173)$ & $146(135 / 161)$ & $136(124 / 151)$ & $113(100 / 149)$ \\
\hline $\mathrm{ML}_{\text {TPA-test }}, \%$ & 100 & 100 & 100 & 100 & 100 & 100 \\
\hline
\end{tabular}

Values are displayed as the median and interquartile range.

was no difference to samples at $37^{\circ} \mathrm{C}$ (197 s [173/204]; $33^{\circ} \mathrm{C}$ vs. $37^{\circ} \mathrm{C}: p=0.1632 ; 37^{\circ} \mathrm{C}$ vs. $39^{\circ} \mathrm{C}: p=0.2081$ ). $\mathrm{MCF}_{\mathrm{FIBTEM}}$ showed no differences between those tem-

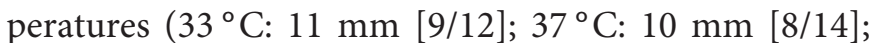
$39^{\circ} \mathrm{C}: 11 \mathrm{~mm}[9 / 14]$; all $\left.p=\mathrm{ns}\right)$.

$\mathrm{LT}_{\text {TPA-test }}$ differed between samples at $33^{\circ} \mathrm{C}$ and $39^{\circ} \mathrm{C}$ (237 s [202/340] vs. $166 \mathrm{~s}$ [154/228]; $p=0.0023$ ) but there was no difference to $37^{\circ} \mathrm{C}(208 \mathrm{~s}$ [184/228]; $p=\mathrm{ns})$. $\mathrm{LOT}_{\text {TPA-test }}$ increased significantly at $33^{\circ} \mathrm{C}(162 \mathrm{~s}$ [134/217]; $p=0.0008)$ compared to $39^{\circ} \mathrm{C}(113 \mathrm{~s}$ [100/149] $)$ but not compared to $37^{\circ} \mathrm{C}$ (136 s [124/151]; $\left.p=0.0732\right)$. There was no difference between samples at 37 and $39^{\circ} \mathrm{C}$ $(p=0.106) . \mathrm{ML}_{\text {TPA-test }}$ of $99-100 \%$ was reached at each temperature.

In the next step we evaluated samples at mild hypothermia compared to thromboelastometric tests at $37^{\circ} \mathrm{C}$. $\mathrm{CFT}_{\text {EXTEM }}$ was prolonged at all temperatures of mild hypothermia $\left(35^{\circ} \mathrm{C}\right.$ : $109 \mathrm{~s}[99 / 126] ; p=0.0002 ; 35.5^{\circ} \mathrm{C}$ : $104 \mathrm{~s}$ [94/110]; $p=0.0025)$ as well as at $36^{\circ} \mathrm{C}(103 \mathrm{~s}$ [91/109]: $p=0.0068)$ compared to $37^{\circ} \mathrm{C}(90 \mathrm{~s}$ [81/105]; Fig. 2a). Moreover, samples at $35^{\circ} \mathrm{C}$ showed prolongation of $\mathrm{CFT}_{\text {EXTEM }}$ compared to those at $36^{\circ} \mathrm{C}(p=0.0358)$. $\mathrm{CT}_{\text {EXTEM }}$ did not differ between either of the tempera-

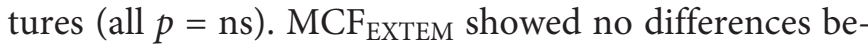
tween either of the temperatures (all $p=\mathrm{ns}$ ).

$\mathrm{CFT}_{\text {INTEM }}$ showed prolongation of all temperatures of mild hypothermia $\left(35^{\circ} \mathrm{C}\right.$ : $94 \mathrm{~s}$ [86/109]; $p=0.0002$; $\left.35.5^{\circ} \mathrm{C}: 91 \mathrm{~s}[80 / 110] ; p=0.0008\right)$ as well as at $36^{\circ} \mathrm{C}(92 \mathrm{~s}$ [79/99]: $p=0.0253)$ compared to $37^{\circ} \mathrm{C}(80 \mathrm{~s}$ [72/88]; Fig. 2b). $\mathrm{CT}_{\text {INTEM }}$ in contrast showed no differences between samples (all $p=\mathrm{ns}$ ).

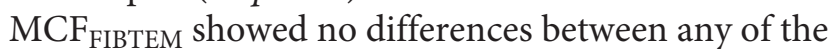
temperatures (all $p=n s$; Fig. $2 \mathrm{e}$ ). $\mathrm{LT}_{\mathrm{TPA} \text {-test }}$ increased at $35^{\circ} \mathrm{C}$ compared to $37^{\circ} \mathrm{C}(249$ s [215/358] vs. $208 \mathrm{~s}$ [184/228]; $p=0.0259)$. There was no difference between the other temperature levels (Fig. 2f). LOT $_{\text {TPA-test }}$ also increased at $35^{\circ} \mathrm{C}$ compared to $37^{\circ} \mathrm{C}(162 \mathrm{~s}$ [141/227] vs. $136 \mathrm{~s}$ [124/151]; $p=0.0223)$. At each temperature, an $\mathrm{ML}_{\text {TPA-test }}$ of $99-100 \%$ could be observed (Table 2).

\section{Discussion}

In this in vitro study we show that both $\mathrm{CFT}_{\text {EXTEM }}$ and $\mathrm{CFT}_{\text {INTEM }}$ were significantly prolonged under mild hypothermia at each evaluated temperature compared to $37^{\circ} \mathrm{C}$. MCF in EXTEM, INTEM, and FIBTEM was not significantly reduced at any level of mild hypothermia. CTs in EXTEM and INTEM significantly increased at $33^{\circ} \mathrm{C}$ compared to $39^{\circ} \mathrm{C}$, but not under mild hypothermia. In the TPA-test both lysis variables LT and LOT increased at $35^{\circ} \mathrm{C}$ compared to $37^{\circ} \mathrm{C}$.

Perioperative mild hypothermia correlates with serious adverse effects, especially increased mortality, cardiac complications, and postoperative wound infection [2-4]. Nonetheless, awareness for temperature monitoring is still in need of improvement [7]. Previous studies show significantly higher blood loss and need for red blood cell transfusions in patients under mild hypothermia $[8,9]$. One of the reasons is that enzyme function is slowed by hypothermia [10]. This is consistent with our findings, as slower clot formation - that is, increased CFT - indicates an increased risk for perioperative bleeding [11].

Clotting times in all tests showed no significant prolongation under mild hypothermia. A priori, one however would presume that a small prolongation in CT un- 
der mild hypothermia should be detected. One explanation for this negative result could be the definition of CT, which is defined as the time from test initiation until a 2-mm clot has been formed. As this small amplitude is hard to detect, some intraindividual variability of CT can be expected. This makes $\mathrm{CT}$ insensitive for small changes and can distort small differences when comparing the different temperature levels. CFT on the other hand is a more robust variable as it is defined as the time from CT to a $20-\mathrm{mm}$ clot. This dimension is easier to detect, and variability is less. This can explain the significant results with CFT but not with CT.

For this reason, we think an additional variable such as "time to twenty" (TT20), which combines CT and CFT, could be more precise when comparing small differences during the initial coagulation process. This parameter was not evaluated before and is therefore not validated yet, but will be part of follow-up studies.

In this context, Shenkman et al. [12] were also not able to detect changes in $\mathrm{CT}$ at mild hypothermia in their model of trauma-induced coagulopathy whereas changes in CFT were observed at $35^{\circ} \mathrm{C}$. Additionally, the group found additive effects of hypothermia and acidosis.

Interestingly, in the TPA-test LOT and LT also showed significant increases under mild hypothermia. Yenari et al. [13] found similar results when they compared TPAinduced fibrinolysis at different temperature levels. This would seem to be a positive effect for coagulation, as it could contribute to in vitro clot stability. Albeit the clot takes longer to form, lysis is also initiated later, which may increase the chance for proper and more stable clot formation. Whether this effect can also be found in vivo warrants further investigation due to the fact that static in vitro conditions cannot be fully transferred to in vivo conditions. Not only the temperature level may influence the later onset of fibrinolysis, but also delayed fibrin formation may be a reason as fibrinolysis depends on aspects of the fibrin surface [14]. Additionally, one has to consider that prolonged fibrinolysis does not help in the case of missing clots due to prolonged clot formation. Nevertheless, this aspect was seen in vitro and should be an aspect of prospective in vivo studies.

Clot firmness expressed by MCF was not altered by mild or excessive hypothermia, correlating with the findings of Kander et al. [6]. This aspect was to be expected as MCF is not time dependent. It does not matter if it takes several hours or only minutes to form the clot. Therefore, we also analyzed time-dependent clot firmness variables like $\mathrm{A} 5_{\text {FIBTEM }}$, but could not detect any differences under mild or excessive hypothermia. Maybe the coarse unit of measurement of $1 \mathrm{~mm}$ can explain this aspect.

ROTEM only focuses on secondary hemostasis. Changes in platelet function and primary hemostasis were not evaluated in this study. In the literature there are various findings on platelet function under hypothermia. On the one hand, platelet aggregation is increased, and platelets are more responsive to activating stimuli. Contributing factors are, for example, lower blood flow, an increase in hematocrit, changes in platelet morphology, and increased expression of adhesion molecules. On the other hand, platelet activators seem to be less available under hypothermia, which could contribute to hypothermia-induced coagulopathy [15]. It can be assumed that the combination of these factors in their totality affects the coagulation process more than a single factor.

\section{Limitations}

Our study has some limitations. First, we evaluated blood samples in vitro and hypothermia probably influences additional processes like blood flow and vasoconstriction, which themselves have an impact on coagulation. Second, we did not evaluate primary hemostasis and platelet function under the conditions of mild hypothermia, which may have additive effects on coagulation. Third, thromboelastometry tests were performed on ROTEM delta analyzers using manual pipetation, which could reduce test reliability. To minimize this effect all tests were performed by one researcher. Standard laboratory tests were not performed, which was done because thromboelastometry represents the whole clotting process whereas standard laboratory tests (e.g., prothrombin time) only represent small parts of the coagulation process. Fourth, we only included young, male volunteers. This was done to minimize the effects of age and sex. Therefore, the results cannot be generalized to all groups of patients. Nevertheless, the findings of this study implicate a negative effect of mild hypothermia on the coagulation process. Future studies will also include female volunteers and patients as well as older participants.

In conclusion, ROTEM showed significant changes under mild hypothermia in vitro. CFT in EXTEM and INTEM was increased compared to $37^{\circ} \mathrm{C}$. In the TPAtest, both LOT and LT were significantly prolonged. These findings illustrate the importance of perioperative temperature management. Even small changes could have an impact on patients' outcomes and temperature should be closely monitored. Nonetheless, further investigation and in vivo testing of coagulation under mild hypothermia is needed.

\section{Statement of Ethics}

The study complied with the guidelines for human studies. The study was approved by the Ludwig Maximilian University ethics committee (No. 19-861). Written informed consent was obtained from subjects and healthy volunteers prior to study inclusion. 


\section{Conflict of Interest Statement}

The authors declare no conflict of interests.

\section{Funding Sources}

The study was funded by institutional resources.

\section{Author Contributions}

S.T.S., T.K., and P.G.: study design. S.T.S., T.K., P.G., A.-C.A., and T.N.: literature search. T.N. and P.G.: data extraction. S.T.S. T.K., and P.G.: assessment of bias. P.G., T.K., S.T.S., T.N., and A.C.A.: data analysis. T.N., P.G., S.T.S., and T.K.: drafting manuscript. P.G., T.N., and A.-C.A.: volunteer recruitment. T.N., P.G., and A.-C.A.: blood sample analysis of patients and volunteers.

\section{Availability of Data and Materials}

The datasets generated and/or analyzed during the current study are available from the corresponding author on reasonable request.

\section{References}

1 National Collaborating Centre for Nursing and Supportive Care (UK). The management of inadvertent perioperative hypothermia in adults. London: Royal College of Nursing (UK); 2011.

2 Forbes SS, Eskicioglu C, Nathens AB, Fenech DS, Laflamme C, McLean RF, et al. Evidencebased guidelines for prevention of perioperative hypothermia. J Am Coll Surg. 2009 Oct; 209(4):492-503.e1.

3 Melling AC, Ali B, Scott EM, Leaper DJ. Effects of preoperative warming on the incidence of wound infection after clean surgery: a randomised controlled trial. Lancet. 2001 Sep;358(9285):876-80.

4 Kiekkas P, Fligou F, Igoumenidis M, Stefanopoulos N, Konstantinou E, Karamouzos $\mathrm{V}$, et al. Inadvertent hypothermia and mortality in critically ill adults: systematic review and meta-analysis. Aust Crit Care. 2018 Jan; 31(1):12-22.

5 Dirkmann D, Hanke AA, Görlinger K, Peters J. Hypothermia and acidosis synergistically impair coagulation in human whole blood. Anesth Analg. 2008 Jun;106(6):1627-32.
6 Kander T, Brokopp J, Friberg H, Schött U. Wide temperature range testing with ROTEM coagulation analyses. Ther Hypothermia Temp Manag. 2014 Sep;4(3):125-30.

7 Torossian A; TEMMP (Thermoregulation in Europe Monitoring and Managing Patient Temperature) Study Group. Survey on intraoperative temperature management in $\mathrm{Eu}$ rope. Eur J Anaesthesiol. 2007 Aug;24(8): 668-75.

8 Schmied H, Kurz A, Sessler DI, Kozek S, Reiter A. Mild hypothermia increases blood loss and transfusion requirements during total hip arthroplasty. Lancet. 1996 Feb;347(8997): 289-92.

9 Rajagopalan S, Mascha E, Na J, Sessler DI. The effects of mild perioperative hypothermia on blood loss and transfusion requirement. Anesthesiology. 2008 Jan;108(1):71-7.

10 Watts DD, Trask A, Soeken K, Perdue P, Dols S, Kaufmann C. Hypothermic coagulopathy in trauma: effect of varying levels of hypothermia on enzyme speed, platelet function, and fibrinolytic activity. J Trauma. 1998 May; 44(5):846-54
11 Görlinger K, Dirkmann D, Solomon C, Hanke AA. Fast interpretation of thromboelastometry in non-cardiac surgery: reliability in patients with hypo-, normo-, and hypercoagulability. Br J Anaesth. 2013 Feb;110(2):222-30.

12 Shenkman B, Budnik I, Einav Y, Hauschner $\mathrm{H}$, Andrejchin M, Martinowitz U. Model of trauma-induced coagulopathy including hemodilution, fibrinolysis, acidosis, and hypothermia: impact on blood coagulation and platelet function. J Trauma Acute Care Surg. 2017 Feb;82(2):287-92.

13 Yenari MA, Palmer JT, Bracci PM, Steinberg GK. Thrombolysis with tissue plasminogen activator (tPA) is temperature dependent. Thromb Res. 1995 Mar;77(5):475-81.

14 Leurs J, Nerme V, Sim Y, Hendriks D. Carboxypeptidase U (TAFIa) prevents lysis from proceeding into the propagation phase through a threshold-dependent mechanism. J Thromb Haemost. 2004 Mar;2(3):416-23.

15 Van Poucke S, Stevens K, Marcus AE, Lancé M. Hypothermia: effects on platelet function and hemostasis. Thromb J. 2014 Dec;12(1): 31 . 